\title{
BOTA PRA FAZER UNIFEI: COMO A APRENDIZAGEM BASEADA EM PROBLEMAS FUNCIONA
}

Fabio Roberto Fowler ${ }^{1}$

Juliana Caminha Noronha ${ }^{1}$

Letícia Tenório ${ }^{1}$

Carolina Renó Ribeiro ${ }^{1}$

${ }^{1}$ Universidade Federal de Itajubá - UNIFEI 


\section{BOTA PRA FAZER UNIFEI: APRENDENDO E COMPETINDO POR BOAS RAZÕES}

Resumo: O interesse por Problem Based Learning (PBL) e Educação Empreendedora (EE) cresceu consideravelmente nos últimos anos e isso desperta a vontade da comunidade acadêmica de implementar tais metodologias. Ambas foram aplicadas ao projeto Bota Pra Fazer UNIFEI. O objetivo do presente estudo é fazer uso de EE por intermédio de um projeto de ação social na busca da formação do engenheiro, analisando assim um Programa de Desenvolvimento de Empreendedorismo. Com resultado tem-se que, fica clara a necessidade de uma maior inserção da PBL e de habilidades empreendedoras, através de Educação Empreendedora, entre as instituições de ensino do país.

Palavras-chave: Aprendizagem Baseada em Problema. Projeto Baseado em Problema. Educação empreendedora. Ação social.

\section{Introdução}

É de conhecimento que com as reformas trabalhistas e previdenciárias acontecendo no Brasil, os formandos nos cursos superiores devem apresentar diferenciais competitivos para o mercado de trabalho, ou seja, apenas conhecimentos técnicos já não são mais suficientes. Aliado às competências gerencias e às 'softs kills', é possível se igualar a empreendedores de sucesso e, assim, apresentar um papel diferenciado tornando-se empreendedor ou intraempreendedor.

A utilização de aprendizagens ativas, como Aprendizagem Baseada em Problemas e Educação Empreendedora, são alternativas de sucesso para auxiliar no ensino dos alunos. Assim, o Centro de Empreendedorismo Unifei, organiza todos os anos, próxima a semana global de empreendedorismo, um evento que possibilita os alunos complementarem seu aprendizado nas 'softs kills' através de ação social.

O Bota Pra Fazer Unifei é uma grande competição de ações de empreendedorismo social. Todo o ano atinge mais de 700 participantes e, em 2015, teve a presença de 788 participantes. O evento aconteceu simultaneamente em Itajubá e Itabira, incluindo alunos, professores e servidores da Universidade Federal de Itajubá. Os grupos participantes concorrem em quatro categorias: Alto Impacto, Criatividade, Mão na Massa e Conhecimentos Técnicos. Visando uma forma da comunidade acadêmica da Universidade Federal de Itajubá retribuir e impactar as cidades de Itajubá e Itabira positivamente, o Bota Pra Fazer Unifei surgiu e impacta em média 30 instituições todos os anos, dentre elas, escolas, ONGs, hospitais e asilos. Como resultado, o Bota Pra Fazer Unifei foi eleito o maior evento de

\section{Organizadores:}
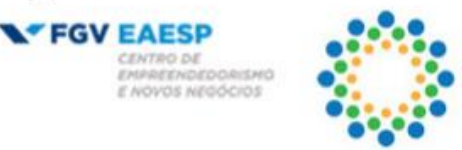

ANEGEPE

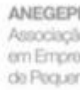

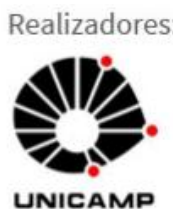

UNICAMP 
empreendedorismo Universitário em 2014 pela Endeavor e parceiros. Cerca de 10\% dos projetos desempenhados durante a semana viram ações regulares na cidade durante o ano, como por exemplo, o Projeto Play e o Taekwondo.

Deste modo, através deste trabalho, procurou-se problematizar a situação da educação brasileira que é carente de iniciativas para o desenvolvimento de habilidades empreendedoras. Para exemplificar uma atividade que envolve aprendizagem baseada em problemas e educação empreendedora foi utilizado o evento Bota Pra Fazer Unifei. Os participantes de 2015 responderam um questionário onde buscava-se encontrar o perfil dos participantes e também se eles acreditavam ter desenvolvido 10 principais habilidades empreendedoras.

Para uma melhor exposição do artigo, este será dividido em duas partes. A primeira parte terá um enfoque mais teórico e abordará referências sobre o tema. Já a segunda parte, por sua vez, terá um enfoque mais prático e abordará os resultados colhidos na pesquisa sobre o evento Bota Pra Fazer Unifei 2015.

\section{Revisão de literatura}

A educação continua a mesma faz alguns anos e isso desestimula os alunos a quererem aprender e buscar novos conhecimentos. Existem quatro maneiras de incentivar as pessoas para se tornarem líderes: preparar as pessoas mais novas antes de começarem a faculdade, criar um diálogo entre as universidades e os líderes locais, repensar e saber mais sobre pequenos negócios e startups. (GERBER, 2014)

Pavlin (2014) acredita que as universidades apresentam um papel que vai além de preparar os alunos para o mercado. Estes alunos precisam sair da faculdade com atributos, habilidades e comportamentos bem desenvolvidos, para isso é necessário introduzir aulas e atividades que apresentem como intuito final desenvolver: planejamento, capacidade de resolução de problemas, liderança, criatividade e trabalho em equipe (BROCKHAUS, 2001; RAE, 1997).

As universidades estão percebendo que oferecer aulas e projetos em empreendedorismo são importantes por conta do crescimento do tema e que assim pode contribuir para o crescimento econômico e ajuda os alunos nas oportunidades de trabalho. Especialistas acreditam que ninguém nasce empreendedor, mas, exposto a fatores que propiciem o desenvolvimento, os mesmos podem aprender e desenvolver habilidades empreendedoras. (NIAN, BAKAR e ISLAM, 2014).

Scramm (2012) realizou uma pesquisa para verificar como as escolas lidam com empreendedorismo. Nos Estados Unidos, pelo menos 600.000 estudantes têm aulas de empreendedorismo todos os anos e há 10 anos atrás, esse número era consideravelmente menor. Mas algo que lhe chamou atenção foi que as escolas não estavam ensinando da maneira correta, pois o tema era apresentado de maneira teórica e poderia ser melhor explorado através de projetos em que os alunos precisam desenvolver e colocar em prática a teoria. E, de acordo com o relatório anual 2014 Youth Entrepreneurship Study, 62\% das universidades não oferecem nenhuma aula de empreendedorismo. Além disso, $37 \%$ dos respondentes da pesquisa disseram que eles tentariam abrir um negócio. Diante desses dados,
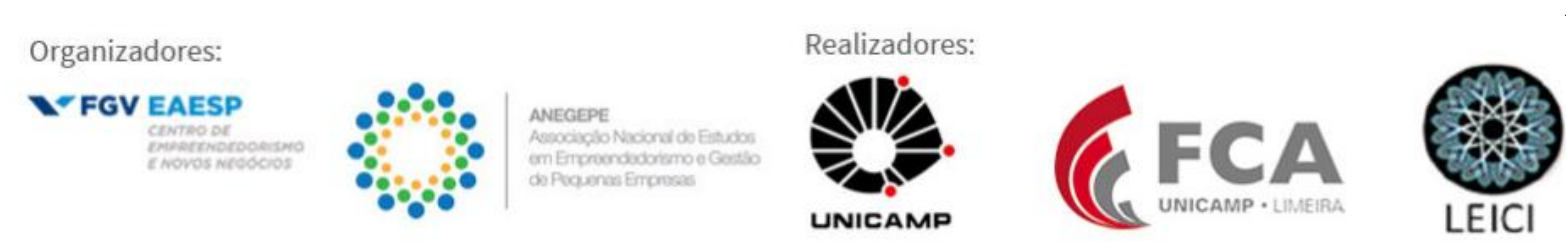
pode-se observar a real importância e necessidade do estudo de empreendedorismo nas universidades.

Diante deste cenário, faz-se necessário a utilização de práticas que não ensinem o aluno apenas a teoria, mas faça-o implementar na prática o que aprendeu. Barrows e Tamblyn (1989) definem aprendizagem baseada em problemas - PBL como "a aprendizagem que resulta do processo de trabalhar para a compreensão de uma resolução de um problema [...] encontrado primeiro no processo de aprendizagem". E, de acordo com Barbara Duch, aprendizagem baseada em problemas é "um método de instrução que desafia os alunos a resolver problemas e a adquirir conhecimentos - 'aprender a aprender' trabalhando em grupos para buscar soluções para problemas do mundo real. Estes problemas são utilizados para envolver a curiosidade dos alunos e iniciar a aprendizagem do assunto. O PBL prepara os alunos para pensar criticamente e analiticamente, e para encontrar e usar recursos de aprendizagem apropriados."

Barrows (2000) define PBL como sendo uma educação autêntica que obriga os alunos a passarem por situações que eles irão vivenciar no mundo real. Ela é considerada importante, pois proporciona ao aluno a aprendizagem a partir do processo de trabalhar para a compreensão ou resolução de problemas autênticos em seus contextos. O PBL envolve quatro aspectos principais: (1) abordagem centrada no aluno, (2) problemas mal estruturados (3) professor como facilitador e (4) autenticidade (BARROWS, 2000).

Juntamente com as práticas do PBL, tem-se a Educação Empreendedora (EE) que é um processo de aprendizagem que auxilia os jovens a desenvolverem competências e motivação para se tornarem empreendedores ou intraempreendedores (ASHMORE et al, 2010). Fowler (1997) afirma que a EE pode ser definida "como sendo um sistema que habilita grupos de pessoas a criarem e dirigirem seus próprios projetos como veículo de aprendizagem". Ela é utilizada para fornecer conhecimento empresarial e habilidades para auxiliar os alunos obterem sucesso na carreira (NIAN, BAKAR E ISLAM, 2014). Além de auxiliar no sucesso da carreira, de acordo com Fowler (1997), a EE proporciona ao indivíduo "atingir graus mais elevados de realização pessoal e bem-estar social".

De acordo com Fowler (1997), "empreendedor é aquele que cria e gerencia projetos", nesta afirmação a palavra projetos não significa apenas empresas, mas pode-se enxergar como qualquer atividade realizada por uma pessoa, incluindo assim os intra-empreendedores. Hashimoto, 2006 define intra-empreendedorismo como “(...) qualquer forma de proposição de mudanças e melhorias na organização ou dentro dos limites da rede direta de relacionamentos da organização que, de alguma forma, se traduz em aumento de valor para o cliente ou para o acionista”.

Ação social pode ser definida, de acordo com McGlone, Espanha, e Mc Glone (2011), como "a doação deliberada e ativa de um tempo, energia, habilidades ou talentos para uma organização de caridade sem receber o pagamento em troca". Cycyora, Claudia e Jessica não consideram contribuições monetárias ou materiais como atos de ação social. As ações sociais, de acordo com Grant (2012), auxiliam a enriquecer os empregos e existem pesquisas que mostram como fazer trabalho social auxilia no desenvolvimento de habilidades (BOOTH et $a l, 2009)$. Além disso, trazem uma maior satisfação e aumenta a produtividade por conta do sentimento de estar causando impacto positivo no ambiente em que está inserido.
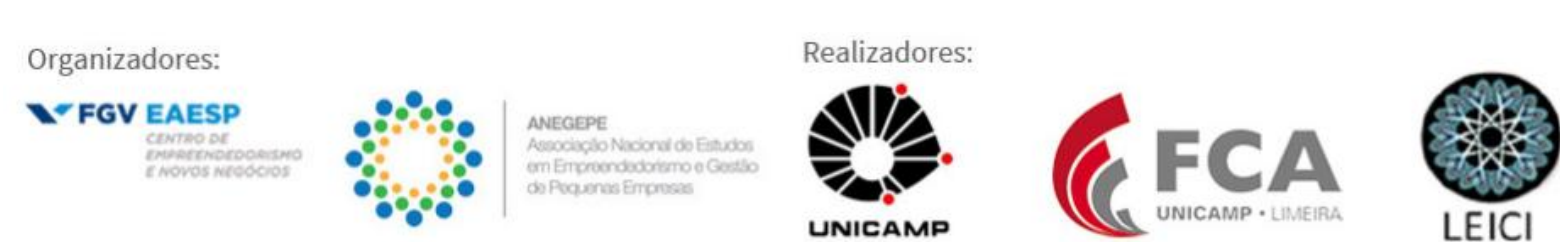
Em contra partida, Dees (1998), Welsh e Krueger (2009) definem empreendedor social como uma pessoa que apresenta como objetivo a criação e sustentação do valor social, envolvendo também inovação contínua e, além disso, exibindo uma responsabilidade para com os constituintes e os resultados. "Os empreendedores sociais perseguem metas e objetivos relacionados à solução de problemas específicos na economia social” (DEES, 1998).

\section{Metodologia}

Nesta seção será apresentada uma pesquisa realizada na Universidade Federal de Itajubá para a compreensão de como o evento Bota Pra Fazer Unifei proporciona a seus participantes o desenvolvimento de habilidades empreendedoras. Esta é uma pesquisa aplicada, pois seus resultados podem ser aplicados ou utilizados na solução de problemas que acontecem no dia a dia. De acordo com Appolinário (2009), diferentemente da pesquisa básica, a pesquisa aplicada estaria mais voltada a objetivos comerciais, ou seja, para o desenvolvimento de novos processos ou produtos orientados para as necessidades do mercado.

O método utilizado para a realização da presente pesquisa foi o Estudo de Caso. O propósito fundamental desse método, segundo Godoy (1995), é a análise intensiva de uma dada unidade social e para Yin (2009) estudo de caso permite uma revisão aprofundada de fenômenos novos ou obscuros, enquanto "retendo as características holísticas e significativas de eventos da vida real". Para Yin (1994), esta modalidade de pesquisa é indicada para investigar um fenômeno contemporâneo dentro de seu contexto, especialmente quando as fronteiras entre o fenômeno e o contexto não são claramente evidentes. Apesar de suas vantagens, é importante que o pesquisador esteja ciente das dificuldades a ele associadas, dentre elas, a dificuldade de generalização de suas conclusões, como recomendam Laville e Dione (1999).

$\mathrm{O}$ método enquadra-se como uma abordagem fundamentalmente qualitativa. $\mathrm{O}$ estudo de caso é adequadamente utilizado quando o investigador busca responder às questões "como" e "porque", questões explicativas que se relacionam a questões operacionais que ocorrem no decorrer do tempo mais do que frequências ou incidências (MARTINS, 2008). De acordo com Gummeson (2004), a pesquisa-ação tradicional envolve: (1) um grupo de pessoas que usam ciclos espirais de atividades que envolvem planejamento, atuação, observação e reflexão sobre o que aconteceu, mostrados esquematicamente na Figura 1; (2) tentar melhorar os processos de ação do grupo de trabalho; (3) que ajudam a resolver problemas complexos e práticos sobre os quais pouco se sabe; (4) produz pelo menos um relatório para a organização do grupo de trabalho sobre o que foi encontrado.

Através do estudo de caso em questão, foi feita a aplicação e análise de questionários a alunos que participaram do evento Bota Pra Fazer Unifei 2015. O presente estudo, resultou no levantamento e coleta de 208 respostas, que representam aproximadamente $26 \%$ dos alunos que participaram do evento.

\section{Resultados e discussões}


A Universidade Federal de Itajubá é uma instituição de ensino superior pública federal, localizada na cidade de Itajubá, no estado brasileiro de Minas Gerais. É considerada a primeira universidade tecnológica e foi a décima escola de engenharia do país. Extremamente conceituada dentre as universidades de engenharia do Brasil, carrega mais de 100 anos de tradição de ensino. Atualmente, conta com 25 cursos superiores, sendo que 14 são engenharias. De acordo com um levantamento quantitativo realizado em novembro de 2017 pela Diretoria de Registros Acadêmicos em parceria com o setor responsável pela tecnologia de informação da Universidade, há na Unifei cerca de 5121 alunos matriculados.

O questionário aplicado apresentava duas vertentes: a primeira era para analisar o perfil do respondente e a segunda sobre as habilidades empreendedoras que havia desenvolvido durante o evento. Em relação as habilidades, teve-se destaque nas seguintes: planejamento, empatia, resolução de problemas, criatividade, liderança, coordenação, envolvimento, flexibilidade, iniciativa e perseverança. Para se analisar a importância de cada uma, era necessário que o entrevistado declarasse o quanto desenvolveu tal habilidade em uma escala de 0 a 5 . A pesquisa coletou 208 respostas sendo que $75 \%$ dos participantes estavam participando pela primeira vez, $13 \%$ pela segunda vez e $10 \%$ pela terceira vez ou mais.

Observando a relação entre a quantidade de vezes que já os alunos já participaram do evento e como eles consideram seu desenvolvimento em cada habilidade observa-se que todos ficaram acima da média, sendo criatividade com a média mais baixa de todos.

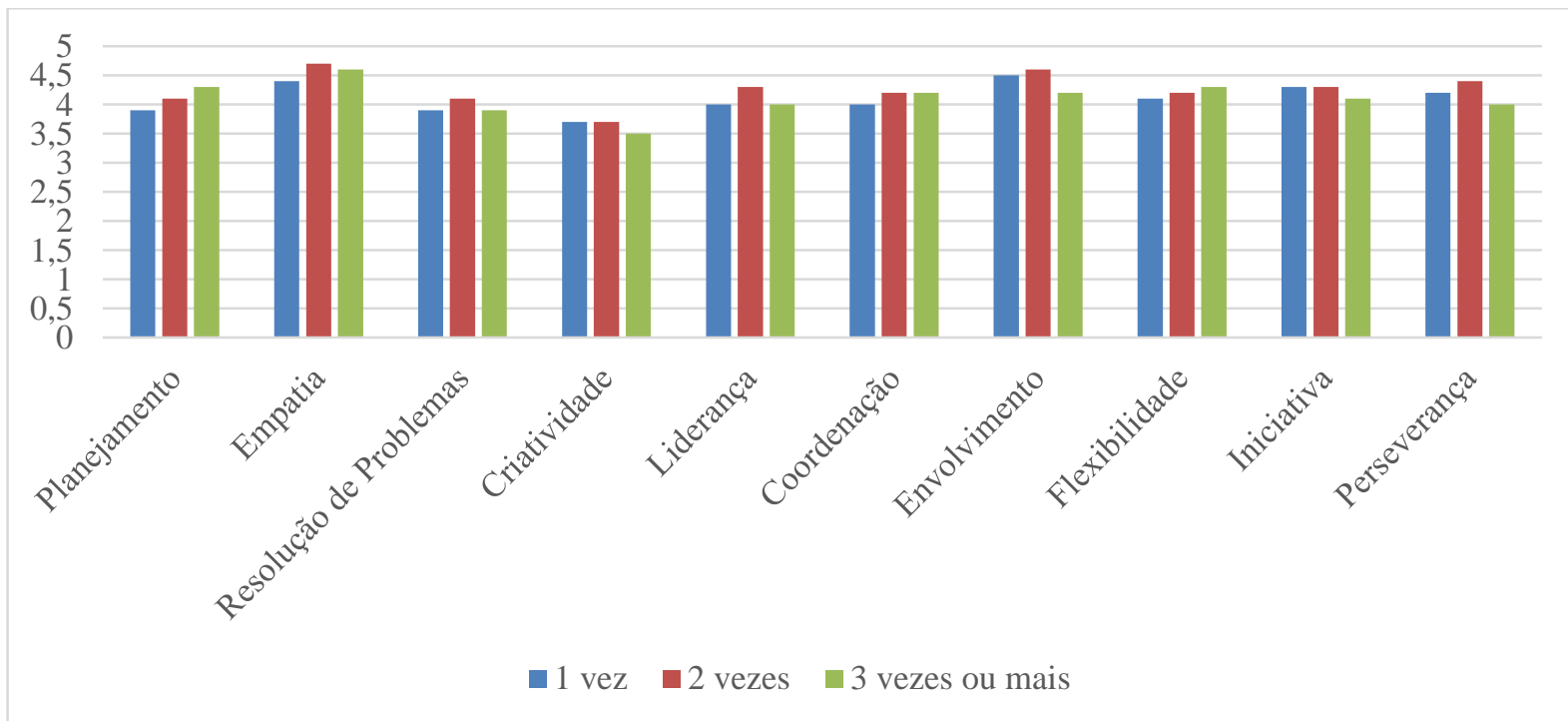

\section{Gráfico 1- Desenvolvimento em cada habilidade}

A Universidade Federal de Itajubá apresenta dois campi (Itajubá e Itabira), uma das pesquisas era referente a qual campi seu projeto foi realizado e, fazendo uma correlação dessa informação com as perguntas sobre as habilidades, observa-se que o campus de Itabira acredita que se desenvolveu mais que o campus de Itajubá. Visto que as médias foram iguais ou superiores às médias de Itajubá. 


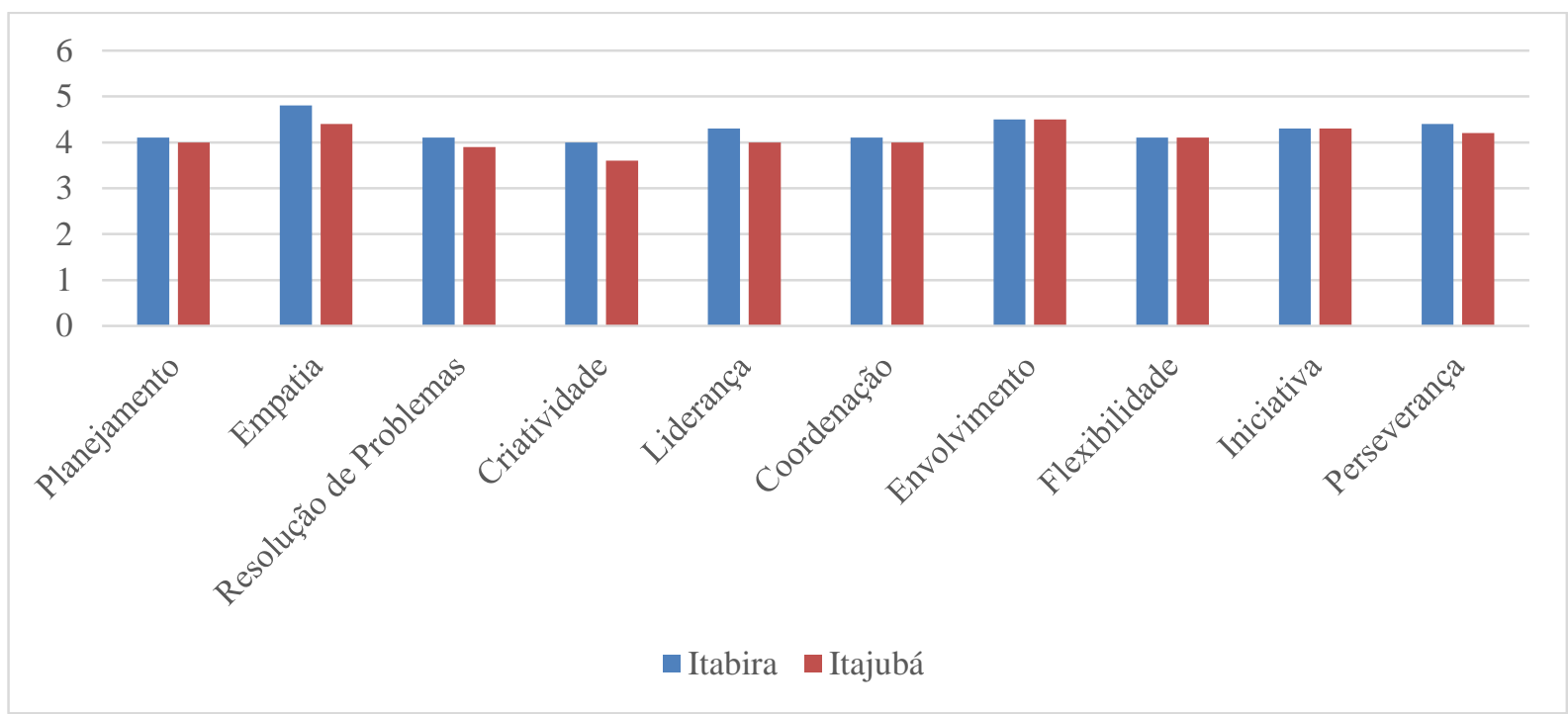

Gráfico 2- Campi em que o projeto foi realizado

Uma das perguntas referia-se à possibilidade do participante se inscrever novamente no ano seguinte para realizar uma nova ação, foram 197 para sim e 11 para não. Comparando as respostas com as notas dadas no desenvolvimento das habilidades pode-se concluir que o fato dos alunos não quererem participar novamente não está ligado ao fato deles não terem desenvolvido as habilidades. Mesmo não tendo interesse em participar novamente, eles dão notas acima da média para o desenvolvimento das habilidades.

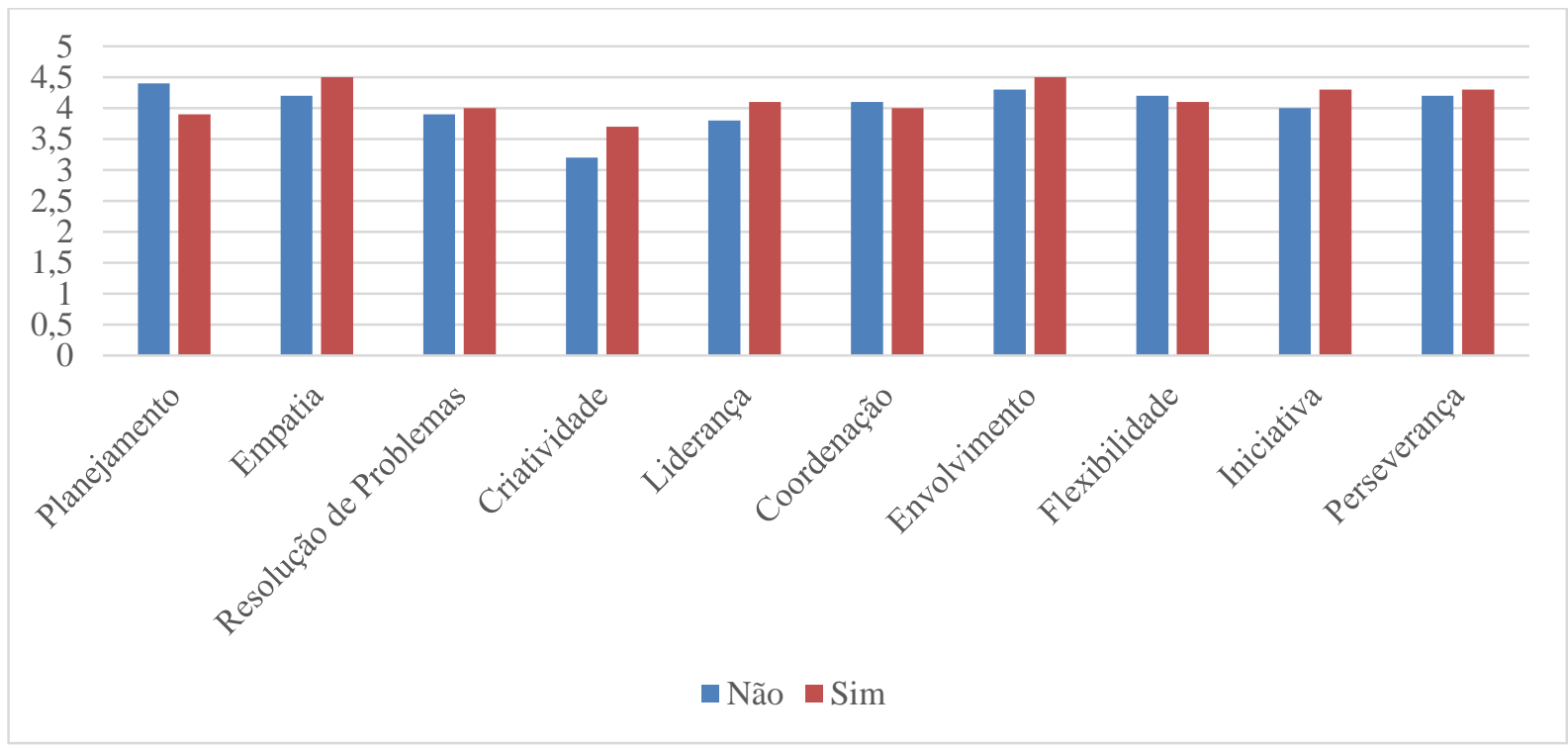

Gráfico 3- Possibilidade de inscrição nos próximos anos 
Observando a média de cada curso, Fisica Bacharelado se destaca como o curso que considera que o evento desenvolve plenamente as habilidades e Engenharia da Computação como o que menos concorda com o desenvolvimento das habilidades.

Um dos desejos do Centro de Empreendedorismo Unifei é tornar o Bota Pra Fazer Unifei uma atividade complementar obrigatória para que os alunos de todos os cursos participem pelo menos uma vez do evento. Então, para saber qual a opinião dos alunos que já participaram do evento, perguntou-se na pesquisa "Você acha que todos os alunos da Unifei deveriam participar, ao menos uma vez, do Bota Pra Fazer Unifei?”. Apenas 5 alunos responderam que não, mas, observando as notas que eles deram para as habilidades, fica explícito que eles acreditam que se desenvolveram, só acreditam que este tipo de atividade não deve ser obrigatória por outro motivo.

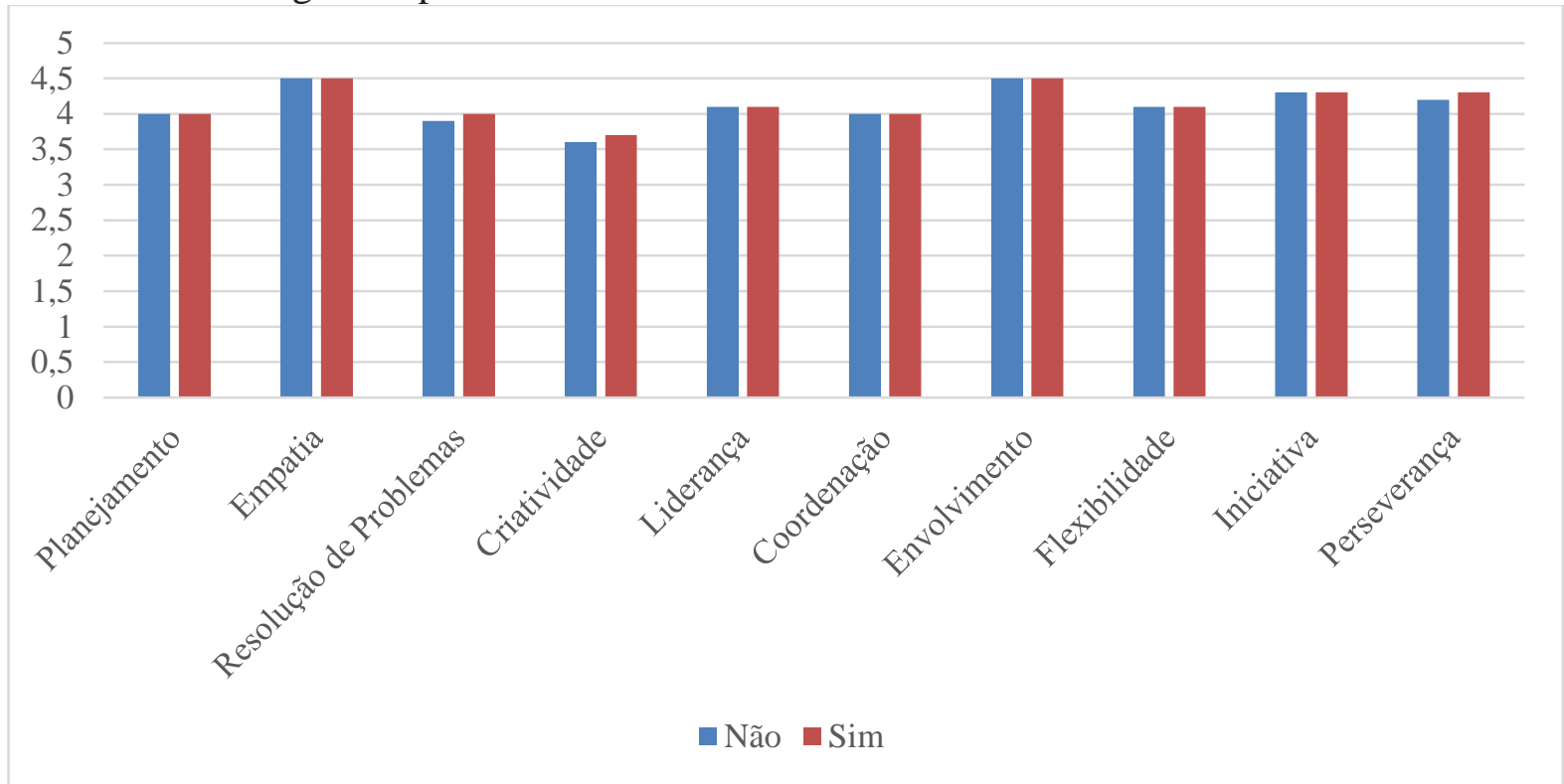

Gráfico 4- Participação obrigatória no evento

Em uma pergunta os alunos deveriam responder o que mais gostaram no Bota Pra Fazer 2015 e é importante destacar algumas observações:

- "A cidade (Itabira) passou a ver a UNIFEI e os alunos de uma forma que antes não conseguiam: as pessoas perceberam que nós, alunos, podemos mudar a cidade para melhor, que não estamos aqui apenas para curtir essa fase da faculdade, viram que não são apenas as festas que movem os universitários e que podemos sim contribuir de maneira positiva para a sociedade. Desejo que o Bota Pra Fazer UNIFEI alcance grandes proporções, que mais pessoas conheçam, participem e que essa ideia seja disseminada por outras universidades."

- "Bota pra Fazer deveria acontecer o ano todo."

- "Gostei de ver que 2015 foi o ano que teve mais discentes e docentes envolvidos no Bota Pra Fazer. E vejo que se continuar assim, a cada ano continuar subindo mais o número de pessoas envolvidas, o Bota Pra Fazer tem tudo para ser maior do que já é." 


\section{Conclusões}

O objetivo deste trabalho foi problematizar a situação da educação que permanece a mesma faz muito tempo e que existem algumas novidades surgindo para tornar este ambiente melhor e mais saudável para a aprendizagem. Buscamos mostrar uma das maneiras de se aprender que é através do evento Bota Pra Fazer Unifei, em que através da aprendizagem baseada em projetos e a educação empreendedora é possível desenvolver as habilidades empreendedoras que o mercado deseja em um profissional.

Para tal conclusão, foi realizado um estudo de caso na Universidade Federal de Itajubá - UNIFEI, local em que o evento acontece. O objetivo da pesquisa era comparar a teoria de Educação Empreendedora e Aprendizagem Baseada em Projetos com o Bota Pra Fazer Unifei 2015.

Depois de uma análise minuciosa pode-se perceber que todos os participantes consideram ter desenvolvido as habilidades empreendedoras acima da média, os participantes do campus de Itabira consideram ter se desenvolvido ainda mais do que os participantes da cidade de Itajubá e grande parte dos participantes participaria novamente do evento. Prova-se assim como as aprendizagens ativas são importantes para o desenvolvimento das softskills e que aliando aprendizagem baseada em problemas e educação empreendedora, os índices de aproveitamento são bem maiores se comparados a aprendizagem baseada apenas em teoria.

\section{Referências}

APPOLINÁRIO, F. (2009) Metodologia da ciência: filosofia e prática da pesquisa. São

Paulo: Cengage Learning. (pp. 209)

BARROWS, H. S. (2000) Problem-based Learning applied to medical education.

Springfield, Illinois, Southern Illinois University School of Medicine.

BARROWS, H. S., \& TAMBLYN, R. M. (1980) Problem-based Learning: an approach to medical education. New York, Springer.

CYCYOTA, Cynthia; FERRANTE, Claudia; SCHROEDER, Jessica (2016). Corporate social responsibility and employee volunteerism: what do the best companies do? Kelley School of Business, (pp. 321-328).

DEES, J.G. (1998) The Meaning of 'Social Entrepreneurship', Unpublished paper funded by the Kauffman Center for Entrepreneurial Leadership, Kansas City, Missouri.

FOWLER, F. R. (1997) Programas De Desenvolvimento De Empreendedorismo: PDEs. Um Estudo De Casos: FEA-USP e DUBS. Master Dissertation (MSc) - Universidade de São Paulo Faculdade de Economia, Administração e Contabilidade, São Paulo.

GRANT, A. (2012) Giving time, time after time: work design and sustained employee participation in corporate colunteering. Academy of management review, (pp. 589615).

GERBER, Scott. (2014) Education needs to factor in entrepreneurship. Harvard Business Review, (pp. 2-4).

GODOY, A. S. (1995) Pesquisa qualitativa: tipos fundamentais. Revista de Administração de Empresas, São Paulo, Vol.35, N.3, (pp. 20-29).

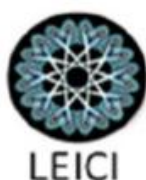


GUMMESSON, Evert; PERRY, Chad. (2004) Action research in marketing. European Journal of Marketing, Vol. 38, N.3/4, (pp. 310-320).

HASHIMOTO, M. Espírito empreendedor nas organizações: aumentando a competitividade através do intra-empreendedorismo. São Paulo: Saraiva, 2006.

LAVILLE, C.; DIONE, J. (1999) A construção do saber: manual de metodologia da pesquisa em Ciências Humanas. Belo Horizonte: Editora UFMG, (pp. 340).

MARTINS, G. A. (2008) Estudo de Caso: Uma Reflexão sobre a Aplicabilidade em Pesquisas no Brasil. Revista de Contabilidade e Organizações, Vol. 2, N. 2, (pp. 8-18).

MCGLONE, T.; SPAIN, J. e MCGLONE, V. (2011) Corporate social responsibility and the millennials. Journal of Education for business. (pp. 195-200).

NIAN, Teh Yi; BAKAR, Rosni; ISLAM Md. Aminul. (2014) Students' Perception on Entrepreneurship Education: The Case of Universiti Malaysia Perlis. International Education Studies; Vol. 7, N. 10.

PAVLIN. (2014) The role of higher education in supporting graduates' early labour market careers, International Journal of Manpower, (pp. 576-590).

SCHRAMM, Carl. (2014) Expanding the entrepreneur class. Harvard Business

Review, (pp. 2).

WELSH, D.H.B. (2014) Creative Cross-Campus Entrepreneurship: A Practical Guide to a Campuswide Program, Palgrave-MacMillan, New York.

YIN, Robert K. (1994) Case study research: design and methods. 2nd edition. Thousand Oaks, CA: Sage, (pp. 171). 